
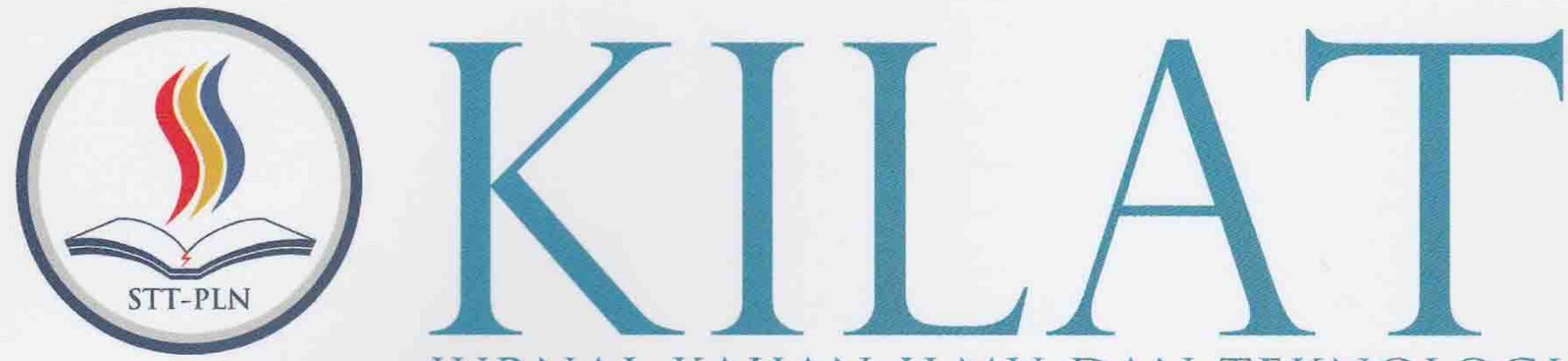

JURNAL KAJIAN ILMU DAN TEKNOLOGI

Endah Lestari: Irma Wirantina K: Ranti Hidayawanti

Faisal:

Muhammad Ridwan: Mardawati

Gita Puspa Artiani: Indah Handayasari

Kresna Ramanda; Irmawati Carolina

Ratna Mutu Manikam:

Farid Setiawan

Rayung Wulan

Roni Kartika Pramuyanti

Rr. Mekar Ageng Kinasti; Djoko Nugroho Notodisuryo

Satria;

Ayu Setiawati Agustini

Syam Gunawan: Pritasari Palupiningsih

Ali Ridho Gumelar: Anton: Ummu Radiyah

M. Yoga Distra Sudirman: Yessy Fitriani
ANALISA TAMAN ATAP DALAM UPAYA MENGURANGI LIMPASAN AIR HUJAN PADA BANGUNAN PERKOTAAN

OPTIMASI DIAGRAM LAYANAN PEMBELIAN DALAM MENDUKUNG MANAJEMEN HUBUNGAN PELANGGAN

OPTIMALISASI PENGOLAHAN SAMPAH ORGANIK DENGAN TEKNOLOGI BIODIGESTER SEBAGAI UPAYA KONSERVASI LINGKUNGAN

SELEKSI FITUR ALGORITMA NEURAL NETWORK MENGGUNAKAN PARTICLE SWARM OPTIMIZATION UNTUK MEMPREDIKSI KELAHIRAN PREMATUR

RANCANG BANGUN MEDIA BELAJAR FISIKA DASAR UNTUK MAHASISWA BERBASIS ANDROID

ANALISIS GLOBAL POSITIONING INFRASTRUKTUR DAN JARINGAN SOSIAL MEDIA DALAM BISNIS APLIKASI TRANSPORTASI DARAT ONLINE DI JAKARTA

PENGARUH INOVASI ANTENA PADA SIARAN TELEVISI MOBIL

PEMANFAATAN LIMBAH PEMBAKARAN BATUBARA (BOTTOM ASH) PADA PLTU SURALAYA SEBAGAI MEDIA TANAM DALAM UPAYA MENGURANGI PENCEMARAN LINGKUNGAN

PENERAPAN METODE GRAPHIC RATING SCALE (GRS) DALAM PENILAIAN KINERJA KARYAWAN

PEMBENTUKAN MODEL KLASIFIKASI DATA LAMA STUDI MAHASISWA STMIK INDONESIA MENGGUNAKAN DECISION TREE DENGAN ALGORITMA NBTREE

IMPLEMENTASI LOAD BALANCING DENGAN ALGORITMA EQUAL COST MULTI PATH (ECMP)

RANCANGAN SISTEM PENILAIAN HASIL KINERJA MULTI COMPANY DAN CROSS BUSINESS SECTOR 


\title{
PEMANFAATAN LIMBAH PEMBAKARAN BATUBARA (BOTTOM ASH) PADA PLTU SURALAYA SEBAGAI MEDIA TANAM DALAM UPAYA MENGURANGI PENCEMARAN LINGKUNGAN
}

\author{
Rr. Mekar Ageng Kinasti ${ }^{1}$; Djoko Nugroho Notodisuryo ${ }^{2}$ \\ Jurusan Teknik Sipil, Sekolah Tinggi Teknik - PLN \\ Email : mekarkinasti75855@gmail.com¹, djoko.n.noto@gmail.com²
}

\begin{abstract}
ABSTRAK
Penelitian tentang pemanfaatan limbah abu batubara dari PLTU ini dilakukan sebagai salah satu upaya penyelamatan lingkungan. Hal ini sebagai dampak melonjaknya permintaan kebutuhan dasar manusia yang salah satunya adalah listrik. Upaya - upaya penyelamatan lingkungan ini merupakan cerminan dari budaya sadar lingkungan (Darling), karena kebersihan lingkungan adalah tanggung jawab seluruh elemen masyarakat. Penelitian pemanfaatan abu dasar barubara (Bottom Ash) sebagai media tanam hidroponik dilakukan pada jenis tanaman Anggrek Bulan, Tomat, dan Sansivieria. Bottom Ash dipergunakan dalam prosentase 0\%, 25\%, 50\%, 75\%, dan 100\%. Masing - masing prosentase media tanam menggunakan Bottm Ash tersebut diulang sebanyak tiga kali. Hasilnya, pada Tanaman Anggrek Bulan media Bottom Ash kurang sesuai digunakan sebagai media tanam. Hal tersebut lebih di karenakan Bottom Ash lebih bersifat alkali (Ph Basa), sedangkan tanaman Anggrek Bulan akan dapat tumbuh maksimal pada kondisi yang Asam - Nomal. Pada tanaman Tomat, Bottom Ash dapat digunakan sebagai media tanam. Selain itu, dengan penambahan Bottom Ash justru mempercepat tumbuhnya benih tomat dari biji menjadi tanaman tomat muda. Tanaman lain yang digunakan dalam penelitian ini adalah Sansivieria. Pada tanaman Sansivieria ini Bottom Ash dapat dipergunakan sebagai media tanam, hal tersebut dapat dilihat dari hasil pengujian kemampuan bertahan tanaman ini terhadap limbah Bottom Ash yang relatif stabil dari awal penelitian sampi akhir penelitian berlangsung. Bottom Ash memiliki kandungan nutrisi yang diperlukan oleh tanaman diantaranya Boron (B), fosfor $(P)$ dan unsur-unsur seperti $\mathrm{Cu}, \mathrm{Zn}, \mathrm{Mn}$, Mo dan Se. sebagian besar abu batubara bersifat alkalis ( $\mathrm{pH}$ 812).
\end{abstract}

Kata Kunci : Bottom Ash, Media Tanam, Hidroponik, Sadar Lingkungan, Pelestarian Lingkungan

\section{ABSTRACT}

This research on the utilization of coal-ash that is wasted at the coal-fired power plant is conducted with the intention to become an effort to alleviate environmental impact of the power plant. The by-production of such waste in coal-fired power plants is a direct consequence of the rising demand on electricity as one of human basic needs in modern lifestyle. Endeavor to save the environment is a manifestation of the good culture of environmental awareness; indeed, human being shall act responsibly for the soundness of the environment. Some sufficient amounts in different composition of coal bottom-ash from a coal-fired power plant mixed with another medium were implemented toward a variety of plants, i.e. a certain type of Orchid ("Moon" Orchid or Phalaenopsis amabilis), Tomato (Solanum lycopersicum), and Sansevieria. A series of mixed medium with different composition (each particular composition is in triplicate), is prepared consisting of $0 \%, 25 \%, 50 \%$. 75\%, and 100\% of Bottom Ash, consecutively. The observed result shows that Bottom Ash is not suitable for the orchid plant as its medium. This more probably results from the fact that the $\mathrm{pH}$ of Bottom Ash tends to be more alkaline, while the Orchid plant would only be growing optimally in acidic - normal condition. In the case of Tomato plant, Bottom Ash is usable to be the plant growing medium; in fact an increase of Bottom Ash percentage expedites the plant growth from its seed to become small plants. Another plant under observation is Sansivieria. Bottom Ash turns out to be suitable as a medium for this plant. In fact, this type of plant remains growing steadily and normally in media with variable percentage of Bottom Ash, all along the research procedure. Bottom Ash contains some nutrient that are beneficial to plants, such as Boron $(B)$, Phosphorus $(P)$ and among other elements are $\mathrm{Cu}, \mathrm{Zn}, \mathrm{Mn}$, Mo dan Se. Most of coal-ashes tend to be alkaline with $\mathrm{pH}$ ranging from 8 to12.

Keywords : Bottom Ash, Plant Growing Medium, Hydroponik, Environmental Awareness, Environmental Conservation.

\section{PENDAHULUAN}

Peningkatan permintaan listrik yang sekarang termasuk kedalam salah satu kebutuhan pokok manusia dan akhirnya mengakibatkan terjadinya lonjakan permintaan akan ketersediaan sumber energi. Proyeksi penggunaan batubara sebagai bahan bakar PLTU hingga tahun 2015 mencapai lebih kurang 80 juta ton/tahun. Oleh karena itu potensi timbulan limbah Bottom Ash dengan type pembakaran dry bottom boiler akan mencapai lebih kurang $4-5$ juta ton/tahun. Fly ash dan Bottom Ash merupakan limbah padat yang dihasilkan dari pembakaran batubara pada pembangkit tenaga listrik. Sebaran Fly ash \& Bottom Ash dipengaruhi oleh gaya gravitasi bumi. Jumlah limbah abu 
batubara yang sangat besar apabila tidak dikelola dan dimanfaatkan dengan benar dapat menimbulkan masalah lingkungan yang serius selain memerlukan tempat penampungan yang sangat luas.

Penelitian ini difokuskan membahas tentang pemanfaatan Abu dasar (Bottom Ash) sebagai limbah PLTU berbahan bakar batubara sebagai media tanam dengan metode hidroponik serta kendala yang mungkin akan muncul pada saat penelitian berlangsung. Hal ini dilakukan sebagai salah satu bentuk upaya kepedulian terhadap lingkungan dalam rangka mengurangi pencemaran lingkungan. Mengingat sampai saat ini pemanfaatan limbah abu batubara belum dapat dilakukan secara masif, sehingga dampak pemanfaatannya belum begitu terasa.

Adapun batasan masalah pada penelitian ini adalah :

a. Penelitian ini menggunakan abu limbah Abu Dasar (Bottom Ash) sisa pembakaran PLTU Suralaya.

b. Limbah abu dasar digunakan sebagai campuran media tanam bersamaan dengan sekam arang dengan prosentase tertentu, yaitu $0 \%, 25 \%, 50 \%, 75 \%$, dan $100 \%$ BA.

c. Pengujian ini dilakukan untuk mengamati sejauh mana kemampuan tanaman untuk dapat bertahan/ tetap tumbuh dengan menggunakan media tanam yang di campur dengan menggunakan abu dasar.

d. Penelitian ini tidak membahas tentang toksisitas yang terkandung dalam tanamannya karena disesuaikan dengan anggaran biaya dan waktu.

e. Tanaman yang dipergunakan untuk pengujian ini adalah Anggrek, Tomat, dan Sansivieria.

Pembangkit listrik tenaga uap (PLTU) adalah pembangkit yang mengandalkan energi kinetik dari uap untuk menghasilkan energi listrik Pembangkit listrik tenaga uap menggunakan berbagai macam bahan bakar terutama batu bara dan minyak bakar serta MFO untuk start up awal. Selain berdasarkan UU No. 32 Tahun 2009, penggolongan fyl ash dan Bottom Ash sebagai limbah B3 (Peraturan Pemerintah Nomor 101 Tahun 2014 tentang Pengelolaan Limbah B3) membuat fly ash dan Bottom Ash harus mendapatkan perlakuan kusus dalam pengelolaannya. Pemahaman yang baik tentang pengelolaan limbah B3 akan mengerucut pada sebuah kesimpulan bahwa pilihan penimbunan sehingga perlu dilakukan kegiatan pemanfaatan sebagai alternatif sebelum landfill (Gambar. 1).

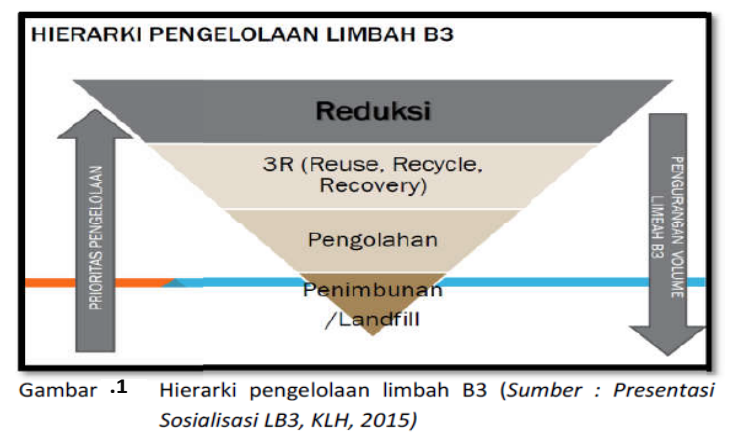

Terminologi Abu Dasar (Bottom Ash) Limbah PLTU

Menurut ASTM C.618, abu terbang didefinisikan sebagai butiran halus hasil residu pembakaran batubara atau bubuk batubara. Bottom Ash merupakan limbah pembakaran batubara yang mempunyai ukuran partikel lebih besar dan lebih berat dari pada fly ash, sehingga Bottom Ash akan jatuh pada dasar tungku pembakaran (boiler) dan terkumpul pada penampung debu (ash hopper) lalu dikeluarkan dari tungku dengan cara disemprot dengan air untuk kemudian dibuang atau dipakai sebagai bahan tambahan pada industri atau kegiatan lainnya. Abu hasil pembakaran merupakan hasil penguraian mineral silikat, sulfat, sulfida, karbonat, dan oksida yang terdapat dalam batubara Limbah fly ash \&Bottom Ash mengandung unsurunsur arsenic (As), barium $(\mathrm{Ba})$, berrylium $(\mathrm{Be})$, boron (B), cadmium (Cd), chromium (Cr), cobalt $(\mathrm{Co})$, copper $(\mathrm{Cu})$, fluorin $(\mathrm{F})$, lead $(\mathrm{Pb})$, mangan $(\mathrm{Mn})$, nikel $(\mathrm{Ni})$, selenium (Se), strontium, thalium (Th), vanadium dan zinc $(\mathrm{Zn})$.
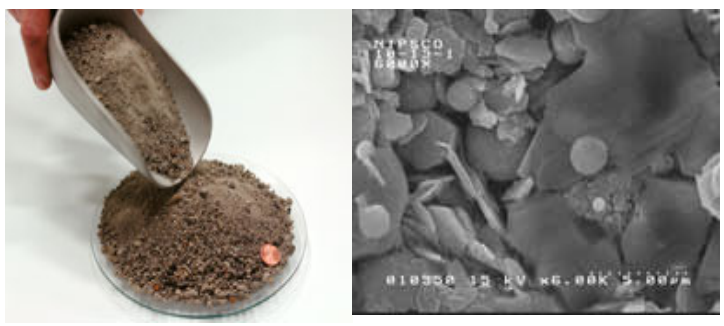

Gambar 2. Bottom Ash limbah PLTU menggunakan bahan bakar batubara Makroskopis (Kiri) dan Mikroskopis (kanan).

\section{Sifat Fisik Bottom Ash}

Sifat fisik Bottom Ash dapat di amati berdasarkan bentuk butirannya, warna, tampilan, ukuran butirannya, specific gravity, dryunit weight dan penyerapan dari wet dan dry. Bottom Ash dapat dilihat pada tabel 1. Berdasarkan warnanya, semakin muda warna abu terbang batubara menunjukkan hasil pembakaran semakin sempurna. Selain itu, warna yang lebih muda juga mengindikasikan kandungan kalsium oksida yang tinggi namun kandungan karbonnya rendah, sedangkan warna yang lebih tua menunjukkan kandungan organik yang tinggi (Marzuki, 2000). Umumnya abu terbang batubara berwarna abu-abu dan bervariasi sampai hitam. Warna abu terbang ini dipengaruhi oleh waktu pembakaran pada tungku (Supriyono, dkk., 1994).

\section{Sifat Kimia Bottom Ash}

Pembakaran batubara lignit dan sub/bituminous menghasilkan abu dengan kalsium dan magnesium oksida lebih banyak daripada bituminus. Namun, memiliki kandungan silika, alumina, dan karbon yang lebih sedikit daripada bituminous (Tabel 2). Fly ash dan Bottom Ash terutama terdiri atas senyawa silicate glass yang mengandung silika (Si), alumina (Al), ferrum (fe), dan kalsium (Ca). Kandungan kecil senyawa lain yang terdapat dalam limbah ini adalah magnesium $(\mathrm{Mg})$, sulfur $(\mathrm{S})$, sodium $(\mathrm{Na})$, potassium $(\mathrm{P})$, dan karbon $(\mathrm{C})$. 
Kandungan bahan berbahaya yang ada dalam fly ash antara lain : arsenic, berilium, boron, cadmium, chromium, cobalt, lead, mangan, merkuri, selenium, strontium, thallium, vanadium, juga mengandung dioksin dan senyawa PAH (Polycyclic Aromatic Hydrocarbon). Berikut merupakan hasil analisa konsentrasi logam berat pada limbah batubara yang telah dilakukan oleh peneliti sebelumnya ( Rhazista Noviardi, 2013) berdasarkan Keputusan Kepala Bapedal No.04/Bapedal/IX/1995 tentang tata cara persyaratan penimbunan hasil pengolahan, persyaratan lokasi bekas pengolahan dan lokasi bekas penimbunan limbah bahan berbahaya dan beracun.

Tabel 1. Sifat fisik penciri dari Bottom Ash

\begin{tabular}{|l|l|l|}
\hline \multicolumn{1}{|c|}{$\begin{array}{c}\text { Sifat Fisik } \\
\text { Bottom Ash }\end{array}$} & \multicolumn{1}{c|}{ Wet } & \multicolumn{1}{c|}{ Dry } \\
\hline Bentuk & Angular / bersiku & Berbutir kecil / granular \\
\hline Warna & Hitam & Abu-abu gelap \\
\hline Tampilan & Keras, mengkilap & $\begin{array}{l}\text { Seperti pasir halus, } \\
\text { sangat berpori }\end{array}$ \\
\hline \multirow{2}{*}{$\begin{array}{l}\text { Ukuran } \\
(\% \text { lolos ayakan) }\end{array}$} & No.4 $(90-100 \%)$ & $1.5 \mathrm{~s} / \mathrm{d} 3 / 4$ in $(100 \%)$ \\
\cline { 2 - 3 } & No.10 $(40-60 \%)$ & No.4 $(50-90 \%)$ \\
\cline { 2 - 3 } & No.40(10\%) & No.10 $(10-60 \%)$ \\
\cline { 2 - 3 } & No.200 (5\%) & No.40 $(0-10 \%)$ \\
\hline Specific gravity & $2,3-2,9$ & $2,1-2,7$ \\
\hline Dry Unit Weight & $960-1440 \mathrm{~kg} / \mathrm{m}^{3}$ & $720-1600 \mathrm{~kg} / \mathrm{m}^{3}$ \\
\hline Penyerapan & $0,3-1,1 \%$ & $0,8-2,0 \%$ \\
\hline
\end{tabular}

Sumber: Coal Bottom Ash/Boiler Slag-Material Description, 2000 [1]

Tabel 2. Komposisi kimia abu batubara berdasarkan tingkat kematangan batubara.

\begin{tabular}{|l|l|l|l|}
\hline Komponen & Bituminous & $\begin{array}{l}\text { Sub- } \\
\text { bituminous }\end{array}$ & Lignite \\
\hline $\mathrm{SiO}_{2}$ & $20-60 \%$ & $40-60 \%$ & $15-45 \%$ \\
\hline $\mathrm{Al}_{2} \mathrm{O}_{3}$ & $5-35 \%$ & $20-30 \%$ & $10-25 \%$ \\
\hline $\mathrm{Fe}_{2} \mathrm{O}_{3}$ & $10-40 \%$ & $4-10 \%$ & $4-15 \%$ \\
\hline $\mathrm{CaO}$ & $1-12 \%$ & $5-30 \%$ & $15-40 \%$ \\
\hline $\mathrm{MgO}$ & $0-5 \%$ & $1-6 \%$ & $3-10 \%$ \\
\hline $\mathrm{SO}_{3}$ & $0-4 \%$ & $0-2 \%$ & $0-10 \%$ \\
\hline $\mathrm{Na}_{2} \mathrm{O}$ & $0-4 \%$ & $0-2 \%$ & $0-6 \%$ \\
\hline $\mathrm{K}_{2} \mathrm{O}$ & $0-3 \%$ & $0-4 \%$ & $0-4 \%$ \\
\hline $\mathrm{LOI}$ & $0-15 \%$ & $0-3 \%$ & $0-5 \%$ \\
\hline
\end{tabular}

Tabel.3. Hasil Analisa Konsentrasi Logam Berat Pada Limbah Batubara.

\begin{tabular}{|c|c|c|c|c|}
\hline \multirow{2}{*}{ No. } & \multirow{2}{*}{ Parameter } & \multirow{2}{*}{$\begin{array}{c}\text { Hasil Analisa } \\
(\mathrm{mg} / \mathrm{kg})\end{array}$} & \multicolumn{2}{|c|}{ Baku Mutu* $(\mathrm{mg} / \mathrm{kg})$} \\
\cline { 4 - 5 } & & & $\mathrm{A}$ & $\mathrm{B}$ \\
\hline 1 & Kadmiun $(\mathrm{Cd})$ & 5,35 & 50 & 5 \\
\hline 2 & Seng $(\mathrm{Zn})$ & 832,87 & 5000 & 500 \\
\hline 3 & Tembaga $(\mathrm{Cu})$ & 27,41 & 1000 & 100 \\
\hline 4 & Timbal $(\mathrm{Pb})$ & 54,26 & 3000 & 300 \\
\hline
\end{tabular}

\section{Abu Batuara Sebagai Media Tanam}

Limbah abu batubara ini, baik abu dasar maupun abu terbangnya memiliki sifat dan komposisi yang relatif sama dengan bentuk asalnya yaitu batubara. Secara kimia, abu batubara merupakan mineral aluminosilikat yang banyak mengandung unsur-unsur seperti $\mathrm{Ca}, \mathrm{K}$, dan $\mathrm{Na}$ selain mengandung unsur $\mathrm{C}$ dan $\mathrm{N}$ dalam jumlah kecil. Salah satu kandungan nutrisi yang diperlukan oleh tanaman dan terdapat di dalam abu batubara diantaranya Boron $(B)$, fosfor $(P)$ dan unsur-unsur seperti $\mathrm{Cu}, \mathrm{Zn}, \mathrm{Mn}$, Mo dan Se. Sebagian besar abu batubara bersifat alkalis ( $\mathrm{pH} 8-12)$.

Dalam penelitiannya Rhazista Noviardi 2013 menjelaskan bahwa beberapa hasil penelitian menunjukkan bahwa abu batubara dapat digunakan sebagai sumber dari kalium, fosfor, kalsium, magnesium, sulfur dan beberapa unsur hara mikro. Tanah yang diberi campuran $35 \%$ abu terbang dan limbah rumah tangga dengan perbandingan 1:1 memberikan peningkatan hasil pada pertumbuhan tanaman. Sehingga dapat dikatakan bahwa abu terbang dan limbah rumah tangga memiliki potensi untuk pemanfaatan pada bidang pertanian (Wong dan Su, 1997).

\section{Pemanfaatan Abu Dasar Batubara (Bottom Ash) Sebelumnya.}

Berikut merupakan pemanfaatan Bottom Ash berdasarkan penelitian - penelitian sebelumnya :

a. FABA sebagai pembenah tanah dan penutrisi tanah pada tanaman Bunga Matahari

b. Pemanfaatan FABA sebagai campuran over burden untuk mencegah air asam tambang

c. Bottom Ashsebagai absorben bahan organik pada air payau

d. Bottom Ashsebagai absorben ion logam $\mathrm{Cd}^{2+}$

e. Bottom Ash untuk bahan baku bio briket

f. Bottom Ashuntuk di daur ulang melalui karbonisasi

g. Bottom Ash sebagai pengganti agregat halus pada pembuatan beton

h. Bottom Ashsebagai agregat buatan pada pembuatan beton

i. Bottom Ashsebagai pengganti dan bahan baku semen

j. Bottom Ashsebagai bahan baku keramik, gelas, batubata, dan refraktori

k. Filler aspal beton, plastik, dan kertas.

\section{Tanaman Hidroponik}

Hidroponik adalah budidaya menanam dengan memanfaatkan air tanpa menggunakan tanah dengan menekankan pada pemenuhan kebutuhan nutrisi bagi tanaman. Kebutuhan air pada hidroponik lebih sedikit daripada kebutuhan air pada budidaya dengan tanah. Penggunaan air pada metode hidroponik menjadi lebih efisien, jadi sesuai diterapkan pada daerah yang memiliki pasokan air yang terbatas. Kunci utama pada metode Hidroponik ini adalah unsur nutrisi (unsur hara) yang dibutuhkan selalu tercukupi.

Berikut merupakan beberapa kelebihan menggunakan metode penanaman hidroponik:

a. Bertanam hidroponik tidak memerlukan lahan luas dan suplay air yang banyak. Hidroponik cukup memaksimalkan lahan terbatas karena tidak membutuhkan lahan yang banyak, karena media tanaman bisa dibuat secara bertingkat.

b. Penanaman hidroponik tidak tergantung oleh musim, karena itu dapat ditanam kapan saja dan dimana saja. 
c. Lahan tempat menanam hidroponik lebih fleksibel, dapat ditanam di mana saja seperti di dalam rumah atau di pekarangan yang sudah dipaving.

d. Bertanam hidroponik lebih hemat jika dibandingan dengan teknik menanam konvensional di atas tanah, karena pada hidroponik tidak perlu menyiramkan air setiap hari.Melalui larutan nutrisi/media larutan mineral yang dipergunakan sudah tertampung di dalam wadah yang dipakai, sehingga hanya melakukan pengontrolan.

e. Bertanam hidroponik lebih ramah lingkungan karena tidak menggunakan pestisida atau obat hama yang dapat merusak tanah, penggunaan air hanya $1 / 20$ dari tanaman biasa, sehingga hasil tanaman hidroponik bisa dimakan secara keseluruhan termasuk akar karena terbebas dari kotoran dan hama.

f. Menggunakan metode hidroponik akan lebih hemat/ mengurangi pemakaian pupuk, sehingga tidak memerlukan banyak tenaga untuk pengerjaannya.

g. Bisa memeriksa akar tanaman dengan jelas secara periodik untuk mengontrol pertumbuhannya, sehingga pertumbuhan tanaman lebih cepat dan kualitas hasil tanaman dapat terkontrol.

h. Lebih hemat energi karena tidak perlu menggunakan kendaraan atau mesin.

i. Tanaman hidroponik dapat terhindar dari bakteri, ulat dan cacing nematoda yang banyak terdapat dalam tanah

\section{Manfaat Penelitian \\ Manfaat Bagi Masyarakat Di Daerah PLTU}

Munculnya sikap sadar lingkungan, hal ini dapat dilihat dengan adanya perubahan sikap dalam menyikapi pengelolaan abu limbah PLTU yang berada di sekitar mereka. Masyarakat akan mengerti dan memahami bahwa tanggung jawab menjaga kelestarian lingkungan adalah tanggung jawab bersama, sehingga memberikan motivasi kepada masyarakat untuk ikut mencoba meneliti atau memanfaatkan abu batubara sebagai limbah PLTU berbahan bakar batubara. Masyarakat menjadi tahu bahwa abu terbang dapat dimanfaatkan sebagai media tanam sehingga di samping menjaga lingkungan dapat digunakan untuk tambahan mata pencaharian.

\section{Manfaat Bagi Penghasil Limbah Abu Dasar} (PLN)

1. Mengurangi timbunan limbah padat abu batubara.

2. Sebagai upaya mewujudkan komitmen bagi PLN untuk menjadikan tenaga listrik sebagai media untuk meningkatkan kualitas kehidupan masyarakat serta menjadikan tenaga listrik sebagai pendorong kegiatan ekonomi dengan berwawasan lingkungan sehingga mampu menyelaraskan penyeimbangan baik aspek ekonomi, sosial, dan lingkungan.

3. Upaya peningkatan pemanfaatan limbah FABA bagi Unit PLTU yang telah beroperasi, membantu pengelolaan dan pemanfaatan limbah PLTU berbahan bakar batubara guna mengurangi pencemaran lingkungan.

4. Sebagai bentuk perwujudan program CSR sebagai wujud nyata dari tanggung jawab sosial perusahaan, dalam meningkatan daya dukung lingkungan guna mengurangi masalah kesehatan lingkungan.

\section{Manfaat Bagi Team Pelaksana}

Keberhasilan penelitian dapat dikatakan sebagai efek samping positif dapat memberikan motivasi kepada pelaksana untuk dapat terus melakukan berbagai hal yang bermanfaat bagi sesama, terus melakukan kegiatan berbasis penelitian juga pengabdian kepada masyarakat, Bangsa dan Negara sebagai implementasi dari ilmu yang didapatkan selama ini serta bentuk tindakan penyelamatan lingkungan.

\section{Luaran Hasil Penelitian} adalah :

Target luaran hasil penelitian yang diharapkan

a. Dihasilkannya tanaman yang bermanfaat sebagai pemecah polutan yang di tanam dengan menggunakan limbah abu dasar PLTU.

b. Limbah abu dasar PLTU dapat digunakan sebagai media tanam alternatif pengganti tanah atau media lain dengan menggunakan metode penanaman Hydroponik, sehingga menanam tetap dapat dilakukan secara lebih bersih dan sederhana.

c. Adanya karya ilmiah berupa jurnal yang diambil dari laporan penelitian berbasis lingkungan ini.

\section{METODOLOGI PENELITIAN}

Penelitian ini dilakukan dengan menggunakan beberapa tahapan, diawali dengan tahapan persiapan berupa studi literatur menggunakan berbagai hasil penelitian sebelumnya sebagai acuan dengan tidak mengurangi kreativitas serta kebebasan dalam melakukan uji penelitian. Selanjutnya peneliti akan melakukan survey lapangan guna mengetahui peralatan apa saja yang diperlukan sehingga mendapatkan gambaran yang lebih jelas dalam perumusan masalah nantinya. Pelaksanaan penelitian terdiri dari beberapa kegiatan seperti perumusan masalah, pengambilan data - data primer, dan skunder dari percobaan yang dilakukan, sampai dengan integrasi keseluruhan data termasuk hasil analisa dilanjutkan dengan tahap ketiga yaitu evaluasi dan keempat adalah tahap pembuatan laporan akhir.

Penelitian dimulai dengan melakukan pengujian terhadap bahan - bahan yang dipergunakan. Hal tersebut dilakukan untuk memastikan bahan - bahan termasuk bibit yang dipergunakan memiliki kualitas yang baik. Pemilihan bibit -bibit tersebut bukanlah tanpa alasan, melainkan dengan menggunakan beberapa pertimbangan, antara lain sebagai berikut :

1. Bunga Anggrek Bulan (Phalaenopsis Seedling)dikarenakan salah satu tanaman yang perlu di budidayakan agar tidak punah. Alasan lain dari pemilihan tanaman ini adalah mampu menyerap polutan Xilena pada udara, 
selain itu tanaman ini dapat mengeluarkan oksigen dimalam hari, sehingga mampu tumbuh subur meskipun di dalam ruangan.

2. Tanaman Sansevieria Disebut juga sebagai tanaman lidah mertua. Tanaman hias yang satu ini bisa ditanam di area luar ruangan. Memiliki daun yang keras, tegak dan ujungnya meruncing. Dapat digunakan untuk menyuburkan rambut, mengobati diabetes, wasir serta kanker ganas. Manfaat lain dari tanaman ini adalah ia ampuh menyerap polusi dan racun, sehingga cocok diletakkan di dalam pot dan disimpan di dalam ruangan.Tanaman ini mempunya kemampuan mengubah $\mathrm{CO} 2$ menjadi oksigen dengan baik di malam hari. Selain itu, tanaman ini juga membersihkan metanal di udara.

3. Tomat, tanaman ini dipilih karena tanaman tomat mempunyai sensitifitas yang sangat tinggi terhadap pencemaran dan kandungan radioaktif serta logam berat pada tanah. Begitu kandungan kimia tanah tercemar makan tanaman ini akan langsung mati, atau jika masih berada dalam ambang batas maka respon tanaman ini adalah buahnya akan berukuran kecil - kecil. Tanaman tomat oleh team peneliti dijadikan sebagai parameter kandungan toksisitas Bottom Ash sehingga nantinya penggunaan Bottom Ash ini tidak membahayakan lingkungan, serta dapat menghasilkan tanaman yang sehat.

Sistem hidroponik yang akan digunakan adalah sistem Wick atau sistem sumbu. Sistem ini dipilih karena sederhana dalam penerapannya, dengan peralatan yang mudah didapatkan dan terjangkau dari segi biaya yang dikeluarkan. Penelitian dilakukan dengan percobaan penanaman bibit beberapa tanaman tersebut dengan menggunakan media tanam berupa arang sekam bakar yang dicampurkan dengan Bottom Ash sebanyak $100 \%, 75 \%, 50 \%, 25 \%$ dan, $0 \%$. Air yang dipergunakan adalah air yang mengandung nutrisi yang diperlukan oleh tanaman sehingga mampu mendukung pertumbuhan tanaman. Air nutrisi yang dipergunakan akan disesuaikan menurut jenis tanamannya.

\begin{tabular}{|c|c|c|c|}
\hline $\begin{array}{c}\text { ProsentaseBA } \\
100 \%\end{array}$ & $\begin{array}{l}\text { 1. Sansevieria } \\
\text { 2. Anggrek }\end{array}$ & $\begin{array}{c}\text { ProsentaseBA } \\
25 \%\end{array}$ & $\begin{array}{l}\text { 1. Sansevieria } \\
\text { 2. Anggrek }\end{array}$ \\
\hline $\begin{array}{c}\text { ProsentaseBA } \\
75 \%\end{array}$ & $\begin{array}{l}\text { 1. Sansevieria } \\
\text { 2. Anggrek }\end{array}$ & $\begin{array}{c}\text { Prosentase } B A \\
0 \%\end{array}$ & $\begin{array}{l}\text { 1. Sansevieria } \\
\text { 2. Anggrek }\end{array}$ \\
\hline $\begin{array}{c}\text { ProsentaseBA } \\
50 \%\end{array}$ & $\begin{array}{l}\text { 1. Sansevieria } \\
\text { 2. Anggrek }\end{array}$ & \multicolumn{2}{|c|}{$\begin{array}{l}\text { Note : Masing - masing perlakuan } \\
\text { diberlakukan pada } 3 \text { jenis bibit tanaman yang } \\
\text { di ujikan dan di ulangi sebanyak } 3 \text { kali. }\end{array}$} \\
\hline
\end{tabular}

Gambar 3. Skema perlakukan pada bibit tanaman yang akan diajukan

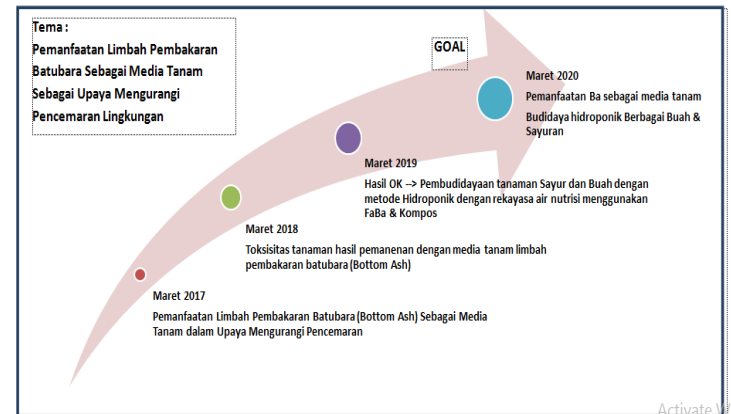

Gambar 4. Road Map Penelitian dimulai dari tahun 2017 s/d tahun 2020.

\section{Persiapan Alat Dan Bahan}

Penelitian dilakukan di halaman rumah di JL. HM. Rahum No.148 Duri Kosambi Cengkareng Jakarta Barat, mengingat benda uji dalam penelitian ini harus mendapat perawatan yang cukup intens. Beberapa persiapan telah dilakukan termasuk pembelian beberapa bahan dan peralatan sebelum dilakukan penanaman. Peralatan yang dipergunakan dalam penelitian ini antara lain :

a. Bak Hydroponik kapasitas 5L

b. Pot tray bibit

c. Kain sumbu (Flanel)

d. Trowel (Cetok Mini)

e. Spray nutrisi

f. Sarung tangan

g. Masker wajah anti debu

h. Karung kresek kapasitas $25 \mathrm{~kg}$

i. Styrofoam

j. Meja tanaman

k. Spidol permanent

I. Alat tulis dan cutter

m. Ember, gayung \& corong

n. Timbangan

o. Gunting tanaman

Bahan - bahan yang digunakan selama penelitian ini berlangsung adalah sebagai berikut :

1. Bottom Ash PLTU Suralaya ukuran medium

2. Bibit remaja Sansivieria

3. Bibit remaja Anggrek Bulan (Phalaenopsis Seedling)

4. Benih Tomat Hidroponik TYMOTI JP

5. Penutrisi AB MIX Trubus

6. Mediapenyemai Rock wool

7. Media Sekam arang bakar

8. Air

\section{Pengujian Bahan}

1. Bottom Ash

Abu dasar atauBottom Ash yang dipergunakan dalam penelitian ini adalah limbah dari PLTU Suralaya. Diambil pada keadaan yang baik (fresh) dan belum terkontaminasi pengotor lain seperti air, pasir, dan lumpur. Abu dasar yang dipergunakan adalah berukuran butir pasir sedang $(1 / 2 \mathrm{~mm})$ sampai dengan halus $(1 / 16$ $\mathrm{mm}$ ) dalam skala ukuran butir (Wentworth Scale).

\section{Pengujian Air}

Pemeriksaan air dilakukan secara visual. Air yang dipergunakan adalah air kualitas 
PALYJA Duri Kosambi Cengkareng Jakarta Barat. Persyaratan air bersih harus dimiliki dalam uji penanaman ini, antara lain air tidak berwarna, tidak berbau, tidak mengandung lumpur serta kandungan minyak dan garam atau tidak berasa.

Hasil pemeriksaan terhadap air yang digunakan selama penelitian ini adalah air termasuk kedalam air bersih menurut SKSNI-S-04-1989-F dan PERMENKES RI NO.416 Th. 1990, yaitu "air bersih adalah air yang dapat digunakan untuk keperluan seharihari dan kualitasnya memenuhi syarat kesehatan dan dapat diminum apabila telah dimasak."

\section{Media Penyemai Rock Wool}

Rockwool dipilih sebagai media penyemaian pada tomat karena dalam hal perbandingan komposisi air dan udara yang dapat disimpan didalamnya, serta mampu menyerap banyak pupuk cair sekaligus udara yang membantu pertumbuhan akar dalam penyerapan unsur hara, mulai dari tahap persemaian sampai pada fase produksi. Rockwool yang dipergunakan dalam penelitian ini adalah rockwool dengan kualitas terbaik produksi dari PT. Trubus Mitra Swadaya.

\section{Media Sekam Arang Bakar}

Media sekam arang yang dipergunkan sebagai media dasar dalam metode Hydroponik yang di pergunakan dalam pengujian ini memiliki kualitas terbaik produksi PT. Trubus Mitra Swadaya

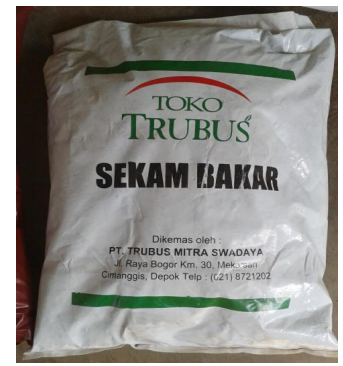

Gambar 5. Sekam Arang Bakar produksi PT. Trubus Mitra Swadaya

\section{Bibit Remaja Anggrek Bulan}

Bibit anggrek yang di pergunakan dalam penelitian ini adalah bibit anggrek sehat berumur remaja sehingga mempunyai kemampuan bertahan hidup lebih tinggi dan siap dipindahkan media penanamannya jika dibandingkan dengan benih atau bibit yang lebih muda.

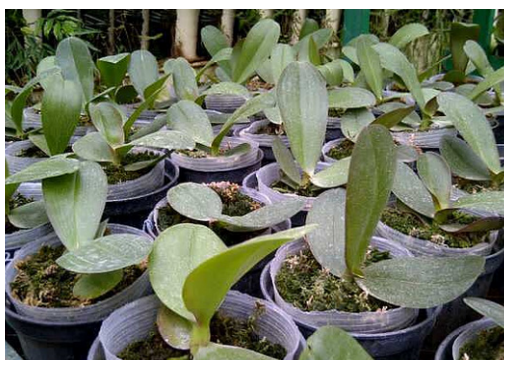

Gambar 6. Bibit Anggrek Bulan berusia remaja

\section{Bibit Remaja Sansivieria}

Bibit sansivieria (Gambar 7.) yang dipergunakan berusia remaja dan dalam keadaan yang sangat baik. Dipilih dari petani sansivieria yang membudidayakan dalam jumlah yang banyak.

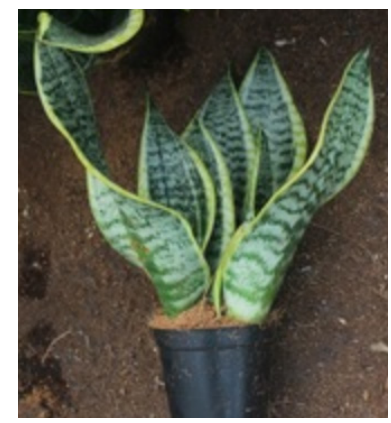

Gambar 7. Bibit Sansivieria remaja

\section{Benih Tomat}

Benih tomat yang dipergunakan adalah Benih Tomat Hidroponik TYMOTI dengan kualitas yang baik (Gambar 9).

\section{Penutrisi}

Penutrisi yang dipergunakan dalam penelitian ini adalah menggunakan penutrisi $A B$ MIX produksi PT. Trubus Mitra Swadaya dengan kualitas yang sangat baik. Penggunaan penutrisi ini untuk memenuhi seluruh unsur makro dan mikro yang di butuhkan oleh tanaman untuk dapat bertahan hidup dan bertumbuh. Unsur mikro seperti Nitrogen $(\mathrm{N})$, Fostat (P), Kalium (K), dan Kalsium (Ca), Sulfur (S) dan Magnesium (Mg), sedangkan unsur makro yang dibutuhkan adalah Besi (Fe), Mangan (Mn), Seng ( $\mathrm{Zn})$, dan Boron (B), dan Molibdenum (Mo).

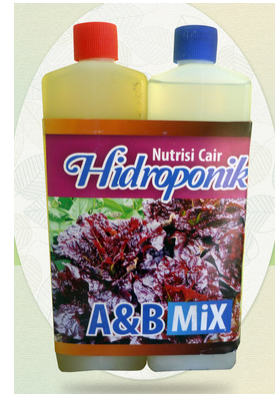

Gambar 8. Penutrisi AB MIX

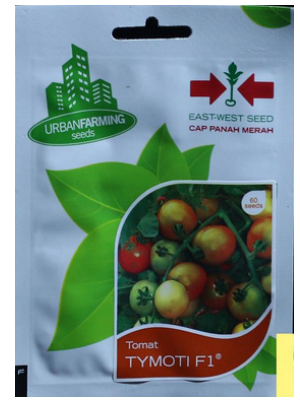

Gambar 9. Benih Tomat yang dipergunakan

\section{HASIL DAN PEMBAHASAN}

\subsection{Pelaksanaan Pengujian Tanaman}

\section{Penimbangan Variasi Bottom Ash}

Pekerjaan yang dilakukan pada tahapan ini adalah menghitung berat isi maksimal pada net pot yang akan dipergunakan untuk menanam. Tanaman jenis tomat dan anggrek di tanam dengan menggunakan wadah yang sama (Net Pot), sedangkan Sansivieria 
di tanam dengan menggunakan pot botol plastik bekas air mineral berukuran 1.5 liter. Penentu yang dipergunakan dalam perhitungan variasi media tanam dilakukan dengan menggunakan Bottom Ash sebagai media utamanya. Satu buah net pot memiliki berat isi maksimal sebesar 100 gram Bottom Ash, sedangkan pada pot botol plastik bekas memiliki berat isi abu dasar maksimal sebesar 400 gr. Masing - masing variasi kandungan Bottom Ash di ulang sebanyak tiga kali pengujian.Variasi campuran media tanam pada penelitian ini dapat dilihat dibawah ini

Tabel 4. Perhitungan be Perhitungan berat isi kandungan Bottom Ash pada nett pot kandungan Bottom Ash pada nett pot

\begin{tabular}{|l|l|c|c|c|c|c|}
\hline \multirow{2}{*}{ No } & \multirow{2}{*}{ Tanaman } & \multicolumn{4}{|c|}{ Perhitungan Kandungan Bottom Ash } \\
\cline { 3 - 7 } & & $\mathbf{0 \%}$ & $\mathbf{2 5} \%$ & $\mathbf{5 0} \%$ & $\mathbf{7 5} \%$ & $\mathbf{1 0 0} \%$ \\
\hline 1 & Anggrek Bulan & $0 \mathrm{gr}$ & $25 \mathrm{gr}$ & $50 \mathrm{gr}$ & $75 \mathrm{gr}$ & $100 \mathrm{gr}$ \\
\hline 2 & Tomat & $0 \mathrm{gr}$ & $25 \mathrm{gr}$ & $50 \mathrm{gr}$ & $75 \mathrm{gr}$ & $100 \mathrm{gr}$ \\
\hline 3 & Sansivieria & - & - & - & - & $100 \mathrm{gr}$ \\
\hline
\end{tabular}

Sumber : Hasil Pengujian

Tabel 5. Perhitungan berat isi kandungan Bottom Ash pada pot

\begin{tabular}{|l|l|c|c|c|c|c|}
\hline \multirow{2}{*}{ No } & \multirow{3}{*}{ Tanaman } & \multicolumn{5}{|c|}{ Perhitungan Kandungan Bottom Ash } \\
\cline { 3 - 7 } & & $\mathbf{0 \%}$ & $\mathbf{2 5 \%}$ & $\mathbf{5 0 \%}$ & $\mathbf{7 5 \%}$ & $\mathbf{1 0 0 \%}$ \\
\hline 1 & Sansivieria & $0 \mathrm{gr}$ & $100 \mathrm{gr}$ & $200 \mathrm{gr}$ & $300 \mathrm{gr}$ & - \\
\hline
\end{tabular}

Sumber : Hasil Pengujian

\section{Anggrek Bulan dan Variasi Penanamannya}

Penanaman tanaman Anggrek Bulan dilakukan dengan variasi kandungan Bottom Ash sebesar $0 \%, 25 \%, 50 \%, 75 \%$, dan $100 \%$. Variasi $0 \%$ dimaksudkan media tanam tidak mengandung Bottom Ash sama sekali, sehingga media tanam yang digunakan adalah murni sekam arang bakar. Penanaman dengan masing - masing variasi Bottom Ash ini dilakukan sebanyak tiga kali.

Tabel 6. Masa bertahan Anggrek Bulan dengan variasi Bottom Ash 0\% pada net pot.

\begin{tabular}{|c|c|c|}
\hline No & Keterangan & Umur (Hari) \\
\hline 1 & Anggrek Bulan 1 & 18 \\
\hline 2 & Anggrek Bulan 2 & 17 \\
\hline 3 & Angrek Bulan 3 & 32 \\
\hline
\end{tabular}

Sumber : Hasil Pengujian

Tabel 7. Masa bertahan Anggrek Bulan dengan variasi Bottom Ash 25\% pada net pot.

\begin{tabular}{|c|c|c|}
\hline No & Keterangan & $\begin{array}{c}\text { Umur } \\
\text { (Hari) }\end{array}$ \\
\hline 1 & Anggrek Bulan 1 & 4 \\
\hline 2 & Anggrek Bulan 2 & 4 \\
\hline 3 & Angrek Bulan 3 & 5 \\
\hline
\end{tabular}

Sumber : Hasil Pengujian
Tabel 8. Masa bertahan Anggrek Bulan dengan variasi Bottom Ash $50 \%$ pada net pot.

\begin{tabular}{|c|c|c|}
\hline No & Keterangan & Umur (Hari) \\
\hline 1 & Anggrek Bulan 1 & 16 \\
\hline 2 & Anggrek Bulan 2 & 16 \\
\hline 3 & Angrek Bulan 3 & 18 \\
\hline
\end{tabular}

Sumber : Hasil Pengujian

Tabel 9. Masa bertahan Anggrek Bulan dengan variasi Bottom Ash $75 \%$ pada net pot.

\begin{tabular}{|c|c|c|}
\hline No & Keterangan & Umur (Hari) \\
\hline 1 & Anggrek Bulan 1 & 20 \\
\hline 2 & Anggrek Bulan 2 & 4 \\
\hline 3 & Angrek Bulan 3 & 5 \\
\hline
\end{tabular}

Sumber : Hasil Pengujian

Tabel 10. Masa bertahan Anggrek Bulan dengan variasi Bottom Ash $100 \%$ pada net pot.

\begin{tabular}{|c|c|c|}
\hline No & Keterangan & Umur (Hari) \\
\hline 1 & Anggrek Bulan 1 & 27 \\
\hline 2 & Anggrek Bulan 2 & 6 \\
\hline 3 & Angrek Bulan 3 & 3 \\
\hline
\end{tabular}

Sumber : Hasil Pengujian

\section{Tomat dan Variasi Penanamannya}

Penanaman tanaman Tomat dilakukan dengan variasi kandungan Bottom Ash sebesar 0\%, 25\%, $50 \%, 75 \%$, dan $100 \%$. Variasi $0 \%$ dimaksudkan media tanam tidak mengandung Bottom Ash sama sekali, sehingga media tanam yang digunakan adalah murni sekam arang bakar. Penanaman dengan masing - masing variasi Bottom Ash ini dilakukan sebanyak tiga kali. Pengamatan pada tanaman Tomat mendapat perlakuan yang sedikit berbeda jika dibandingkan dengan tanaman lain. Hal tersebut karena Tomat memerlukan penyemaian biji sebelumnya, sehingga pengamatan pada Tomat meliputi lama waktu tumbuhnya bibit dan masa bertahan bibit tomat tersebut.

Tabel 11. Masa bertahan Tomat dengan variasi Bottom Ash $0 \%$ pada net pot.

\begin{tabular}{|c|c|c|c|}
\hline No & Keterangan & $\begin{array}{c}\text { Tumbuh } \\
\text { Bibit }\end{array}$ & $\begin{array}{c}\text { Umur s/d } \\
\text { Akhir } \\
\text { penelitian }\end{array}$ \\
\hline 1 & Tomat 1 & 0 & 0 \\
\hline 2 & Tomat 2 & 0 & 0 \\
\hline 3 & Tomat 3 & 0 & 0 \\
\hline
\end{tabular}

Sumber : Hasil Pengujian 
Tabel 12. Masa bertahan Tomat dengan variasi Bottom Ash $25 \%$ pada net pot.

\begin{tabular}{|c|c|c|c|}
\hline No & Keterangan & $\begin{array}{c}\text { Tumbuh } \\
\text { Bibit (Hari) }\end{array}$ & $\begin{array}{c}\text { Umur s/d } \\
\text { Akhir } \\
\text { penelitian }\end{array}$ \\
\hline 1 & Tomat 1 & 0 & 0 \\
\hline 2 & Tomat 2 & 14 & 27 \\
\hline 3 & Tomat 3 & 0 & 0 \\
\hline
\end{tabular}

Sumber : Hasil Pengujian

Tabel 13. Masa bertahan Tomat dengan variasi Bottom Ash $50 \%$ pada net pot.

\begin{tabular}{|c|c|c|c|}
\hline No & Keterangan & $\begin{array}{c}\text { Tumbuh } \\
\text { Bibit } \\
\text { (Hari) }\end{array}$ & $\begin{array}{c}\text { Umur s/d } \\
\text { Akhir } \\
\text { penelitian }\end{array}$ \\
\hline 1 & Tomat 1 & 0 & 0 \\
\hline 2 & Tomat 2 & 0 & 0 \\
\hline 3 & Tomat 3 & 0 & 0 \\
\hline
\end{tabular}

Tabel 14. Masa bertahan Tomat dengan variasi Bottom Ash $75 \%$ pada net pot.

\begin{tabular}{|c|c|c|c}
\hline No & Keterangan & $\begin{array}{c}\text { Tumbuh } \\
\text { Bibit }\end{array}$ & $\begin{array}{c}\text { Umur s/d } \\
\text { Akhir } \\
\text { penelitian }\end{array}$ \\
\hline 1 & Tomat 1 & 13 & 33 \\
\hline 2 & Tomat 2 & 12 & 22 \\
\hline 3 & Tomat 3 & 13 & 25 \\
\hline
\end{tabular}

Sumber : Hasil Pengujian

Tabel 15. Masa bertahan Tomat dengan variasi Bottom Ash $100 \%$ pada net pot.

\begin{tabular}{|c|c|c|c|}
\hline No & Keterangan & $\begin{array}{c}\text { Tumbuh } \\
\text { Bibit }\end{array}$ & $\begin{array}{c}\text { Umur s/d } \\
\text { Akhir } \\
\text { penelitian }\end{array}$ \\
\hline 1 & Tomat 1 & 10 & 33 \\
\hline 2 & Tomat 2 & 12 & 33 \\
\hline 3 & Tomat 3 & 10 & 33 \\
\hline
\end{tabular}

Sumber : Hasil Pengujian

\section{Sansivieria dan Variasi Penanamannya}

Penanaman tanaman Sansivieria dilakukan dengan variasi kandungan Bottom Ash sebesar 0\%, 25\%, $50 \%, 75 \%$, dan $100 \%$. Variasi $0 \%$ dimaksudkan media tanam tidak mengandung Bottom Ash sama sekali, sehingga media tanam yang digunakan adalah murni sekam arang bakar. Baik penanaman dengan variasi $0 \%, 25 \%, 50 \%, 75 \%$, maupun $100 \%$ Bottom Ash, masing - masing dilakukan sebanyak tiga kali. Pengujian yang dilakukan pada tanaman Sansivieria ini di lakukan dengan dibatasi selama 33 hari sama seperti kedua jenis tanaman yang lain.
Tabel 16. Masa bertahan Sansivieria selama 33 hari pada net pot.

\begin{tabular}{|c|c|c|c|}
\hline \multirow{2}{*}{$\begin{array}{c}\text { Prosentase } \\
\text { Bottom Ash }\end{array}$} & \multicolumn{3}{|c|}{$\begin{array}{c}\text { Umur Tanaman } \\
\text { SansivieriaDalam 33 Hari }\end{array}$} \\
\cline { 2 - 4 } & 1 & 2 & 3 \\
\hline $0 \%$ & 30 & 31 & 33 \\
\hline $25 \%$ & 31 & 30 & 33 \\
\hline $50 \%$ & 32 & 32 & 33 \\
\hline $75 \%$ & 33 & 33 & 33 \\
\hline $100 \%$ & 33 & 33 & 33 \\
\hline
\end{tabular}

Sumber : Hasil Pengujian

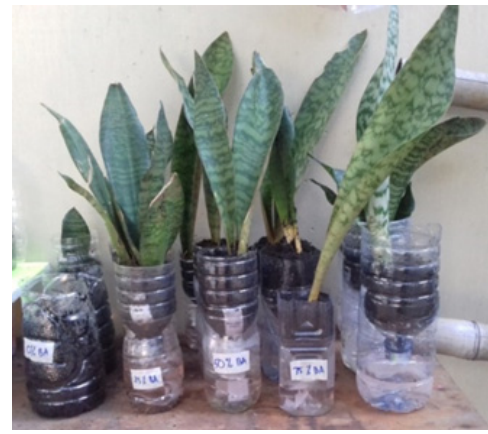

Gambar 10. Penanaman Sansivieria dengan variasi Bottom Ash 0\%, 25\%, 50\%, 75\%, dan 100\%

(Dari kiri ke kanan)

\section{Pengujian Pertama}

Berdasarkan hasil pengujian pada tanaman Anggrek Bulan, Tomat maupun Sansivieria, dimulai dari prosentase $0 \%$ Bottom Ash sampai dengan $100 \%$ Bottom Ash, dimana ketiga jenis tanaman masing - masing prosentase di ulangi sampai tiga kali. Grafik pertama (Grafik 1.) menunjukkan tren umur masing - masing jenis tanaman Anggrek Bulan 1, Tomat 1, dan Sansivieria 1 adalah semakin meningkat, bahkan dapat bertahan hidup.

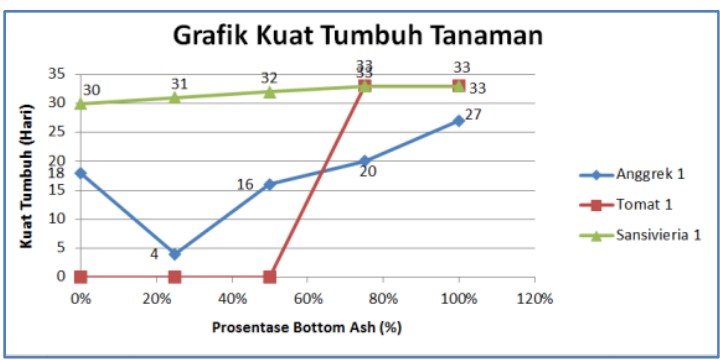

Grafik 1. Kuat tumbuh tanaman Anggrek Bulan 1, Tomat 1, dan Sansivieria 1 (Sumber : Hasil Pengujian)

\section{Pengujian Kedua}

Pengujian kedua dilakukan dengan waktu mulai yang sama dengan pengujian pertama, dilakukan selama 33 hari. Pada pengujian kedua di dapatkan tren yang tidak jauh berbeda pada tanaman Sansivieria 2 yaitu relatif semakin banyak kandungan Bottom Ash maka umurnya semakin lama. 
Tanaman Anggrek menunjukkan perilaku yang tidak stabil jika di bandingkan dengan pada saat pengujian pertama. Prosentase 0\% Bottom Ash memiliki umur Anggrek sebanyak 17 hari, prosentase $20 \%$ umurturun menjadi 4 hari, prosentase $50 \%$ umur tanaman Anggrek Bulan kembali naik menjadi 16 hari, pada prosentase $75 \%$ kembali turun menjadi 4 hari, dan pada prosentase $100 \%$ Bottom Ash umur tanaman Anggrek Bulan naik menjadi 6 hari.

Tanaman Tomat pada prosentase Bottom Ash $0 \%$ tidak tumbuh sampai hari terakhir sehingga nilai kuat tumbuhnya dianggap 0 , prosentase ke $25 \%$ Tomat mengalami pertumbuhan pada hari ke 14 dan mampu bertahan sampai dengan hari ke 33.

Pertumbuhan pada prosentse $50 \%$ tidak seperti harapan, benih Tomat mengalami penurunan masa tumbuh dari prosentase sebelumnya, sampai hari ke 33 belum dijumpai tanda - tanda benih pecah menjadi bibit Tomat. Prosentase ke $75 \%$ dan $100 \%$ tomat menunjukkan perubahan semakin baik jika di bandingkan dengan prosentase Bottom Ash $50 \%$. Prosentase $75 \%$ dan $100 \%$ benih tomat tumbuh pada hari ke 12. Prosentase $75 \%$ mampu bertahan hidup sampai hari ke 22 sedangkan prosentase 100\% Bottom Ash mampu bertahan hidup sampai 33 hari

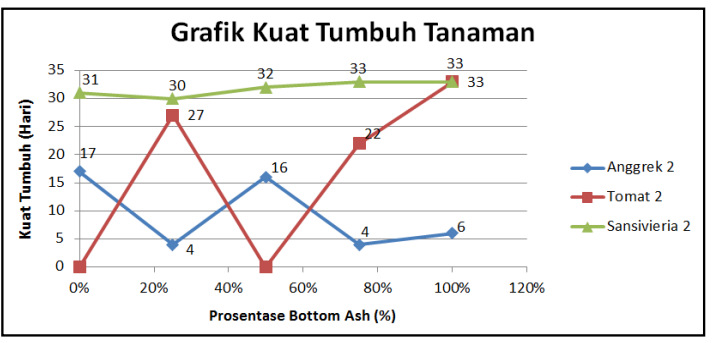

Grafik 2. Kuat tumbuh tanaman Anggrek Bulan 2, Tomat 2, dan Sansivieria 2 (Sumber: Hasil Pengujian).

\section{Pengujian Ketiga}

Anggrek Bulan pada pengujian ketiga memiliki tren yang tidak beraturan. Prosentase $0 \%$ memiliki umur 32 hari, prosentase $25 \%$ berumur 5 hari, prosentase $50 \%$ berumur 18 hari, prosentase $75 \%$ mampu bertahan sampai dengan umur 5 hari saja, sedangkan prosentase $100 \%$ hanya bertahan dalam waktu 3 hari. Tanaman Tomat memiliki model grafik yang hampir sama dengan pengujian pertama. Pada prosentase $0 \%$ benih tidak tumbuh sama sekali sampai hari ke 33, demikian pula pada prosentase $25 \%$ dan $50 \%$. Perubahan mulai nampak pada prosentase $75 \%$, benih Tomat tumbuh pada hari ke 13 dan mampu bertahan selama 25 hari, sedangkan pada prosentase 100\% Bottom Ash tomat tumbuh pada hari ke 10 dan mampu bertahan sampai hari ke 33 .

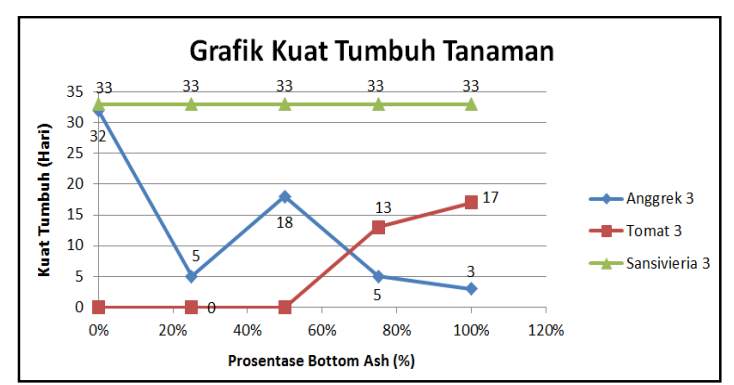

Grafik 3. Kuat tumbuh tanaman Anggrek Bulan 3, Tomat 3, dan Sansivieria 3 (Sumber : Hasil Pengujian)

\section{Kendala Yang Di Hadapi}

Kendala yang dihadapi selama penelitian berlangsung antara lain sebagai berikut:

a. Ukuran butir Bottom Ash yang terlalu halus jika dipakai untuk metode Hydroponik, sehingga megalami kesulitan menentukan net pot yang sesuai dan menjamin media tidak larut ke dalam cairan penutrisi.

b. Anggrek Bulan memiliki karakteristik tersendiri dalam perawatan dan penanganannya, dapat dikatakan Anggrek khususnya Anggrek Bulan ini hanya akan tumbuh dalam kondisi angin, air dan $\mathrm{pH}$ air yang sesuai sedangkan dalam penelitian ini tidak dilakukan pengukuran $\mathrm{pH}$ air yang di gunakan untuk melarutkan nutrisi karena keterbatasan dana.

c. Menjaga tanaman dari faktor eksternal selama proses penelitian berlangsung menjadi salah satu kendala yang di hadapi, cuaca yang tidak menentu, air hujan dan sinar matahari langsung serta gangguan dari hewan - hewan liar seperti kucing juga tikus sangat mungkin terjadi, hal tersebut sangat mempengaruhi kelangsungan hidup tanaman.

\section{KESIMPULAN}

1. Berdasarkan hasil pengujian pada penelitian ini, dapat di tarik kesimpulan bahwa Bottom Ash dapat digunakan sebagai media tanam Hydroponik pada jenis tanaman Anggrek, Tomat, dan Sansivieria karena memiliki kandungan nutrisi yang diperlukan oleh tanaman diantaranya Boron (B), fosfor $(P)$ dan unsur-unsur seperti $\mathrm{Cu}, \mathrm{Zn}, \mathrm{Mn}$, Mo dan Se. sebagian besar abu batubara bersifat alkalis (pH 8-12),

2. Penggunaan Bottom Ash sebagai media tanam belum dapat direkomendasikan secara umum dikarenakan belum dapat diketahui toksisitas hasil tanamannya mengingat tidak dilakukan uji toksisitas pada tanaman yang di tanam dengan menggunakan media tanam Bottom Ash.

3. Umur hasil pengujian relatif bervariasi, tidak menunjukkan model tertentu/ tidak dapat memenuhi prediksi tertentu, baik pada prosentase rendah maupun pada prosentase Bottom Ash yang tinggi, hal tersebut dapat dipengaruhi oleh faktor - faktor eksternal seperti kecepatan angin, kelembaban udara 
yang tidak stabil, sinar matahari, juga gangguan dari binatang liar seperti tikus dan kucing.

4. Bottom Ash terbukti dapat membantu meningkatkan laju pertumbuhan, yaitu pada benih tanaman Tomat. Pada prosentase Bottom Ash yang lebih besar benih lebih cepat bertumbuh menjadi bibit Tomat.

5. Pada tanaman Anggrek Bulan, Bottom Ash kurang sesuai jika digunakan sebagai media tanam, karena Anggrek akan dapat tumbuh optimal jika disiram menggunakan air dengan ph 5 - 7 sedangkan sifat Bottom Ash yang relatif basa karena bersifat alkalis dengan $\mathrm{pH} 8-12$.

6. Bottom Ash dapat digunakan sebagai media tanam pada Sansivieria, hampir seluruh pengujian yang di lakukan pada jenis tanaman ini berhasi dilakukan dan Sansivieria dapat bertahan hidup.

7. Ukuran butir Bottom Ash yang sesuai untuk digunakan sebagai media tanam hidroponik adalah Bottom Ash berukuran kerikil atau lebih dari $2 \mathrm{~mm}$ (Wentworth Scale).

8. Dengan menggunakan Bottom Ash sebagai media tanam, diharapkan pemanfaatan limbah abu dasar batubara dapat semakin masif disamping pemanfaatan yang dilakukan dalam bidang konstruksi, karena selayaknya permasalahan lingkungan yang di akibatkan oleh kegiatan manusia adalah menjadi tanggung jawab seluruh manusia.

\section{DAFTAR PUSTAKA}

\section{Jurnal}

Munir, Misbachul. 2008. Pemanfaatan Abu Batubara (Fly ash) untuk Hollow Block yang Bermutu Dan Aman Bagi Lingkungan. Semarang: Universitas Diponogoro

Rahmat Kurniawan, Ali , dkk. 2010. Penelitian Pemanfaatan Abu Batubara PLTU Untuk Penimbunan Pada Pra Reklamasi Tambang Batubara.

Noviardi Rhazista., Limbah Batubara Sebagai Pembenah Tanah dan Sumber Nutrisi : Studi Kasus Tanaman Bunga Matahari (Helianthus Annus), Jurnal RISTEK Geologi dan Pertambangan,ISSN 0125-9849 Ris.Geo.Tam Vol. 23, No.1, Juni 2013 (61-72).

\section{Buku}

Direktorat Jenderal Pengelolaan Sampah, Limbah dan B3, Kementerian Lingkungan Hidup dan Kehutanan Yogyakarta, 1 Februari 2016,Mekanisme Pengelolaan Dan Perizinan Pemanfaatan Limbah B3 Pada PLTU Batubara, Yogyakarta

Tanjung, 1993, Materi Kuliah IImu Lingkungan Jurusan teknik Sipil UGM, Yogyakarta.

Universitas Pembangunan Nasional "Veteran" Jogjakarta, Jurusan Teknik Geologi, Pengantar Ilmu Lingkungan, Jogjakarta.

\section{Disertasi}

PLN (Persero),PT, 1 - 2 Februari 2016, Workshop Pemanfaatan FA BA, Jogjakarta

Sugiharto, Eko, 2016, Implementasi Pemanfaatan Fly Ash \&Bottom Ash Dari PLTU Batubara, Pusat Studi Lingkungan HidupUniversitas Gadjah Mada, Yogyakarta.

Wardani, Sri Prabandiyani Retno. 2008. Pemanfaatan Limbah Batubara (Fly ash ) Untuk Stabilisasi Tanah Maupun Keperluan Teknik Sipil Lainnya dalam Mengurangi Pencemaran Lingkungan. Semarang: Universitas Diponogoro.

Wibowo A. \& Gatsmir, W. 2003. Penelitian Bahan Bangunan dari Abu Terbang Batubara Paiton dan Suralaya dan Pengaruhnya Terhadap Lingkungan. Puslitbang TEKMIRA. Bandung.

\section{Internet}

Khaerunisa, Herni. Toksisitas Abu Terbang dan Abu Dasar Limbah PLTU Batubara yang Berada di Sumatera dan Kalimantan Secara Biologi. www.tekmira.esdm.go.id/kp/Batubara/toksisita s.asp. Di akses pada tanggal 04 Oktober 2013 pukul 19.45 Wita

PUSLITBANG Teknologi Mineral Dan Batubara Badan Litbang Energi Dan Sumber Daya Mineral.

http://litbang.esdm.go.id/halaman/puslitbangte k-mineral-dan-batubara 